\title{
SOCIEDADES DE CONTROLE: \\ A INTERPRETAÇÃo DELEUZEANA DE FOUCAUlT
}

\author{
Elton CORBANEZI*
}

\begin{abstract}
RESUMO: Este estudo pretende mostrar como o conceito de sociedades de controle - elaborado por Deleuze no início dos anos 1990 como diagnóstico das sociedades contemporâneas - provém da atualização que o autor realiza de Foucault ao interpretá-lo de modo singular. Nesse sentido, analisamos, inicialmente, como a noção aparece de forma embrionária em Um novo cartógrafo, texto em que Deleuze aborda Vigiar e punir no ano de publicação deste livro que se tornou incontornável no debate contemporâneo sobre controle social. Em seguida, investigamos as características do conceito deleuzeano de sociedades de controle, mostrando como os contornos de tal noção figura de maneira limitada na obra foucaultiana. Por fim, sugerimos que Deleuze captou o programa crítico de Foucault em Vigiar e punir ao formular um conceito cuja capacidade diagnóstica permanece atual na medida em que contribui para a análise do desenvolvimento das redes e dos dispositivos tecnológicos de controle.
\end{abstract}

PALAVRAS-CHAVE: Sociedades de controle. Relações de poder. Deleuze. Foucault.

Depois de investigar e de interpretar rigorosamente e à sua maneira o pensamento de Michel Foucault, Gilles Deleuze (1992) elabora um diagnóstico

UFMT - Universidade Federal de Mato Grosso. Instituto de Ciências Humanas e Sociais. Programa de Pós-Graduação em Sociologia. Departamento de Sociologia e Ciência Política. Cuiabá - MT - Brasil. 78060-900 - eltonrcorbanezi@gmail.com. https://orcid.org/0000-0003-2802-7259. 
preciso de nossa atualidade mediante a expressão conceitual sociedades de controle. Dele consta o curto, porém percuciente, Post-Scriptum sobre as sociedades de controle [1990] que se subdivide em três tópicos - Histórico, Lógica e Programa que podem levar o leitor a crer que está diante de uma ficção científica a desvelar o futuro. Contudo, não é o que se passa, como o próprio Deleuze (1992, p.224225) explicita ao abrir a seção Programa: "Não há necessidade de ficção científica para se conceber um mecanismo de controle que dê, a cada instante, a posição de um elemento em espaço aberto, animal numa reserva, homem numa empresa (coleira eletrônica)". Com efeito, levando adiante a imaginação de Félix Guattari de que um dia cartões eletrônicos poderiam ser utilizados para superar barreiras, de modo a assegurar a mobilidade dos indivíduos, o autor de Post-scriptum adverte que o importante não é a barreira, mas o computador que detecta a posição dos indivíduos - lícita ou ilícita - e opera, dessa maneira, uma modulação universal. O célebre texto do filósofo francês estabelece assim o diagnóstico penetrante de uma nova experiência e formação sócio-histórica, cuja aurora é contemporânea ao surgimento e desenvolvimento da Internet nos anos 1990, sendo que os desdobramentos da nova configuração social, baseada em mecanismos de controle em vias de implantação em todo o tecido social após a constatação da crise das instituições disciplinares, devem constituir o objeto privilegiado de estudos sócio-técnicos.

É desta forma que Deleuze (1992) institui uma nova maneira de pensar as sociedades contemporâneas. Para ele, não estaríamos mais em sociedades disciplinares - localizadas por Foucault nos séculos XVIII, XIX e início do XX -, mas em sociedades de controle, que constituem um modo de devir e de atualização daquelas, não sem rupturas. Em seu Post-Scriptum, ele apresenta, portanto, o declínio do confinamento e da função estritamente disciplinar tanto em instituições ordinárias (escola, caserna e fábrica) quanto em instituições extraordinárias (manicômio e prisão), destinadas aos indivíduos que fogem às regras dos poderes normalizadores anteriores.

Sabe-se que, nas sociedades disciplinares, por meio de linguagem e regulamentos análogos em distintas instituições, o indivíduo não cessa de recomeçar, passando de um espaço fechado a outro, nos quais a finalidade consiste sempre em disciplinar os corpos, moldando-os e tornando-os politicamente dóceis e economicamente úteis ${ }^{1}$. Para Deleuze (1992), no entanto, em vez de confinado exclusivamente em instituições, o homem contemporâneo circula nos meios abertos endividado, uma vez que nas sociedades de controle ele se encontra, a todo instante,

\footnotetext{
1 "[...] [P]rimeiro a família, depois a escola ('você não está mais na sua família'), depois a caserna ('você não está mais na escola'), depois a fábrica, de vez em quando o hospital, eventualmente a prisão, que é o meio de confinamento por excelência" (DELEUZE, 1992, p. 219).
} 
em um controle contínuo, sem início, meio e fim - isto é, de forma processual ${ }^{2}$. É nesse sentido que ele lança mão de $O$ processo, romance em que Kafka (1997) teria antecipado o cruzamento dos dois tipos de sociedade ao construir a personagem de Joseph K. em torno da ideia de sua dívida infinita para com a sociedade em todas as dimensões (jurídica, econômica, social, existencial); e diante da impossibilidade de quitar a dívida, restar-lhe-ia suportar a moratória ilimitada ou prorrogação indefinida ("l'atermoiement illimité"), expressão que Deleuze emprega tanto em Post-Scriptum (1992) quanto anteriormente em Un nouveau cartographe ( Surveiller et punir ») para mostrar como Kafka descrevia em seu romance a passagem de um regime jurídico para outro - para as sociedades disciplinares, a expressão apropriada é quitação aparente.

Com efeito, o texto Um novo cartógrafo - publicado inicialmente em 1975 na revista Critique, ano em que Vigiar e punir (FOUCAULT, 1987) veio a lume, e modificado e expandido posteriormente para a publicação de Foucault em $1986^{3}$ pode indicar a gestação e a formação da noção de sociedade de controle, elaborada por Deleuze mediante interpretação e desdobramento singulares do pensamento de Foucault. Nesse sentido, o emprego da expressão moratória ilimitada e seu corolário (o endividamento permanente) apresentam uma relevância significativa, na medida em que permitem apreender uma rede de controle que atravessa também os meios livres, prescindindo do espaço fechado da prisão e de qualquer outra instituição disciplinar. É que o aprisionamento de Joseph K. já não necessita de condenação nem de prisão, que constituem o núcleo disciplinar em termos do enunciável (direito penal) e do visível (a prisão e o panoptismo como agenciamento visual). Desse modo, a passagem em que o autor recorre ao universo kafkiano ressalta, em 1975 - quinze anos antes de Post-Scriptum, portanto -, um aspecto essencial do diagnóstico concretizado posteriormente: a ideia de controle processual e contínuo no espaço aberto da sociedade, no qual circulam indivíduos livres. "A prisão enquanto segmentaridade rígida (celular) remete a uma função flexível e móvel, a uma circulação controlada, a toda uma rede que atravessa também os meios livres e pode aprender a se passar de prisão" (DELEUZE, 1986, p. 50, tradução nossa).

É preciso observar, contudo, que o controle é um mecanismo intrínseco à tecnologia de poder disciplinar: controla-se o corpo, o tempo, o gesto, o trabalho. Um dos aspectos da alteração, portanto, reside na forma e na extensão: nas sociedades

\footnotetext{
2 Para contrastar os dois modelos sócio-históricos, ver Operários ao sair da fábrica, documentário em que Farocki (1995) mostra como a relação de oposição entre dentro e fora se apresenta de forma nítida e central nas sociedades modernas disciplinares, e I thought I was seeing convicts, em que o documentarista alemão evidencia a eficácia dos dispositivos de controle para além de regimes de condenação (FAROCKI, 2000).

3 Conforme Nabais (2009), não há modificação substancial entre as duas edições de 1975 e 1986 no que diz respeito à interpretação deleuzeana de Vigiar e punir, a partir da qual procuramos mostrar, de maneira específica, o aspecto embrionário do conceito de sociedades de controle.
} 
contemporâneas o controle não se dá apenas em instituições, mas no espaço aberto do tecido social, o que implica efetivamente maior extensão de sua ação. De maneira nenhuma, porém, a disciplina inspira liberdades, como acredita-se experimentar no contexto das sociedades de controle: o controle disciplinar incide sobre o corpo, por exemplo, através do aprisionamento, do treinamento, da modelação. A esse respeito, posteriormente, na conferência Qu'est-ce que l'acte de création? [1987], em que a noção de sociedades de controle parece figurar pela primeira vez na obra de Deleuze (2003a), o autor fora explícito:

Um controle não é uma disciplina. Com uma estrada não se enclausuram pessoas, mas, ao fazer estradas, multiplicam-se os meios de controle. Não digo que esse seja o único objetivo das estradas, mas as pessoas podem trafegar até o infinito e "livremente", sem a mínima clausura, e serem perfeitamente controladas. Esse é o nosso futuro. (DELEUZE, 2003a, p. 300, tradução nossa).

Para compreender o projeto de Foucault (1987) em Vigiar e punir, em que o cerne da questão consiste em apreender o modo operatório da tecnologia de poder disciplinar próprio da modernidade, Deleuze estrutura Um novo cartógrafo em duas partes. Na primeira, o filósofo explicita as teses do livro de Foucault mediante a crítica a seis postulados que caracterizariam o pensamento tradicional de esquerda, aí compreendido o marxismo; todos diretamente relacionados ao poder, os postulados se referem à propriedade, à localização, à subordinação, à essência ou ao atributo, à modalidade e à legalidade. De modo esquemático, Deleuze (1986, p. 32-38) afirma respectivamente que i) o poder é menos propriedade de uma classe dominante do que posições estratégicas a partir de que se torna possível exercê-lo; ii) para além de qualquer centralização estatal ou global, o poder é difuso e local, embora não seja facilmente localizável, já que se dissemina por todo o tecido social; iii) há articulação entre diferentes segmentos, sem totalização ou unificação como se o poder derivasse exclusivamente de um modo de produção (infra-estrutura); iv) em vez de essência ou atributo que qualifica os que o detém, o poder é puramente operatório e relacional (relação de forças); v) o poder não opera necessariamente por violência, repressão ou negação da realidade (ideologia) - ele é positivo, produz realidade, verdades, saberes, discursos, comportamentos; vi) no lugar da oposição lei-ilegalidade, a lei se constitui como gestão de ilegalismos, permitindo algumas ilegalidades como privilégios da classe dominante ou tolerando outras como compensação às classes dominadas ${ }^{4}$.

\footnotetext{
${ }_{4}$ Ainda que perpasse toda a sua obra, a concepção de poder de Foucault - que não elaborou uma teoria sistemática sobre o assunto - figura especialmente em poucas páginas de Vigiar e punir (FOUCAULT, 1987, p. 25-29), de História da sexualidade I (FOUCAULT, 2010, p. 102-108) e, de modo específico, em Sujeito e Poder (FOUCAULT, 1995, p. 239-245). Embora seja empregada com frequência no singular, a noção de poder é sempre múltipla, o que se depreende da concepção relacional de forças.
} 
Na segunda parte, e de modo complementar à síntese das teses mediante a crítica a postulados, o autor de $O$ Anti-Édipo (DELEUZE; GUATTARI, 2010) e de Mil platôs (DELEUZE; GUATTARI, 1997) investiga rigorosamente determinados conceitos foucaultianos mesclando-os com sua própria criação conceitual em parceria com Guattari. Resulta desse tipo de procedimento paralelos entre diagrama - expressão que Foucault teria empregado apenas uma vez, segundo Deleuze $(1986, \text { p. } 42)^{5}-\mathrm{e}$ máquina abstrata, assim como entre dispositivo e agenciamentos concretos.

Grosso modo, o diagrama ou máquina abstrata - que devem ser lidos em Um novo cartógrafo como conceitos sinonímicos ${ }^{6}$ - consistem em um tipo de mapa ou cartografia que abrange todas as dimensões sociais, ou melhor, em uma exposição das relações de força que constituem o poder e sua função de ensinar, de educar, de tratar, de fazer trabalhar, de punir etc. Já os agenciamentos concretos, que Deleuze (1986) introduz a partir da noção foucaultiana de dispositivos ${ }^{7}$, são os efeitos de máquinas abstratas, a efetuação delas - por exemplo: a máquina abstrata do regime disciplinar de poder produz escolas, prisões, oficinas, quartéis, fábricas e hospitais. Segundo Deleuze (1986), máquina abstrata e agenciamentos concretos constituem assim dois polos, em que se passa de um ao outro de forma insensível. Os agenciamentos se distribuem em segmentos duros, compactos, separados, constituídos de descontinuidades formais: escola, exército, oficina, hospital, prisão. Apesar de separados, tais agenciamentos concretos se comunicam essencialmente através da efetuação da máquina abstrata, "de forma que todos se parecem, e a prisão se estende através dos outros, como as variáveis de uma mesma função sem forma, de uma função contínua (a escola, a caserna, a oficina já são prisões...)" (DELEUZE, 1986, p. 48, tradução nossa). Dessa maneira, o filósofo explicita a tese foucaultiana de Vigiar e punir (1987), segundo a qual a base do modelo disciplinar reside na forma-prisão, de modo que o sistema carcerário constitui apenas o limite do diagrama, sua radicalidade. A diferença, portanto, é de grau, visto que a máquina abstrata ou diagrama operam de forma mais tênue na escola do que na prisão.

Para o nosso propósito, o importante a reter é que o modo operatório do poder não é estático. Como sustenta Deleuze, todo diagrama ou máquina abstrata

\footnotetext{
5 Em 1986, durante seu curso sobre o tema do poder em Foucault, Deleuze afirma com ênfase a raridade do termo aos seus ouvintes: "Há uma página de Foucault em que ele emprega uma vez uma palavra que me parece bastante importante, bastante esclarecedora para o conjunto de sua teoria, é a palavra diagrama. E eu insistirei enormemente sobre o diagrama, ainda que a palavra só tenha sido empregada por Foucault uma vez, mas em uma página essencial" (Cours Foucault - Le Pouvoir, tradução nossa). Disponível em: http://www2.univ-paris8.fr/deleuze/article.php3?id_article=437).

6 "O diagrama não é mais o arquivo, auditivo ou visual, é o mapa, a cartografia, coextensiva a todo campo social. É uma máquina abstrata" (DELEUZE, 1986, p. 42, tradução nossa).

7 Embora faça operar o conceito de dispositivo no primeiro volume de História da sexualidade, é em entrevista que Foucault (1979, p. 244-247) o esclarece pormenorizadamente. Sobre o conceito, ver também Deleuze (2003, p. 316-325) e Agamben (2005), que o interpretam, cada um à sua maneira, a partir de Foucault.
} 
é intersocial e se encontra sempre em devir. "Há uma história dos agenciamentos, assim como há um devir e mutações de diagrama" (DELEUZE, 1986, p. 49, tradução nossa), e de um diagrama a outro - sustenta Deleuze (1986, p. 51, tradução nossa) a partir de sua leitura singular de Foucault - "outros mapas são traçados", ou seja, novas relações de força reconfiguram o exercício do poder. Ora, a noção de moratória ilimitada sugere, no texto publicado inicialmente em 1975, que o controle opera no espaço aberto da sociedade e que, por conseguinte, são insuficientes para a análise do presente os diagramas soberania e disciplina, que se aplicam a outras configurações sócio-históricas. Com isso, a expressão moratória ilimitada e a ideia que ela veicula desempenham, a nosso ver, um duplo papel na leitura de Deleuze: de um lado, elas podem ser entendidas como corroboração da tese de que os diagramas se encontram em constante devir; de outro, elas explicitam a exigência de criação de um novo conceito para analisar a sociedade em sua forma atual. É a partir da ideia de devir e de sucessão de diagramas, conjugada com a constatação de que o controle incide sobre o espaço aberto, que pode então emergir não apenas a possibilidade como também a necessidade de formular posteriormente o conceito e o diagnóstico das sociedades de controle, como um novo diagrama que cartografa o poder no tecido social contemporâneo. Não apenas ruptura com o diagrama disciplinar, a noção de sociedades de controle consiste também em sua atualização, que estabelece, contudo, a passagem para uma outra função: em vez de modelar a conduta do indivíduo enclausurado no espaço restrito e seriado das instituições, trata-se de modular a vida do indivíduo livre, incitando-o e gerindo-o integralmente no espaço aberto da sociedade. Como se vê, tal função se assemelha ao que Foucault $(2005 ; 2010)$ designou como uma biopolítica da população. Contudo, para o autor de História da sexualidade: a vontade de saber (FOUCAULT, 2010), a biopolítica, não obstante sua posterioridade em termos analíticos, coexiste com a disciplina em determinado momento histórico, ao passo que para Deleuze (1992) as sociedades de controle a sucedem.

II

Em que consiste então a nova cartografia do poder designada por Deleuze (1992) como sociedades de controle e de que modo o filósofo apresenta este conceito profícuo para análise das sociedades contemporâneas? Diferenciando os diagramas, o autor afirma em Post-scriptum:

O controle é de curto prazo e de rotação rápida, mas também contínuo e ilimitado, ao passo que a disciplina era de longa duração, infinita e descontínua. O homem não é mais o homem confinado, mas o homem endividado (DELEUZE, 1992, p. 224). 
De acordo com a diferença sócio-histórica das redes de poder, passamos da soberania à disciplina, que, por sua vez, oferece as condições de possibilidade para a consolidação do controle como a forma mais sofisticada de dominação. A cada tipo de sociedade corresponde um tipo de máquina, sustenta Deleuze (1992, p. 216): as máquinas simples ou dinâmicas, como a roda utilizada como instrumento de tortura no suplício medieval, convêm às sociedades de soberania em que opera o imperativo fazer morrer e deixar viver; as máquinas energéticas condizem com as sociedades disciplinares, cujo modelo reside no modo de produção serial das fábricas; as cibernéticas e os computadores, enfim, constituem dispositivos de controle nas sociedades contemporâneas, em que os perigos não são mais a greve ou a sabotagem, mas a interferência, a pirataria, a introdução de vírus e a detecção de rastros. Nas atuais sociedades de controle, portanto, não se trata mais de identificar o indivíduo e sua posição na massa por meio de assinatura e número, como ocorre no modelo disciplinar, mas de fazê-lo mediante cifra ou senha que fornecem acesso à informação do sujeito dividual - um sujeito que, através da máquina de informática, se torna um corpo de dados, um corpo-informação, passível de divisão ${ }^{8}$. É desse modo que a informação veiculada por senhas, cifras e navegações virtuais pode rastrear e detectar a posição lícita ou ilícita de cada indivíduo em suas comunicações instantâneas, produzindo como efeito o controle contínuo.

Constatando a emergência do controle ininterrupto no espaço aberto do corpo social, Deleuze (1992, p. 216) afirma, não sem ironia, que o confinamento mais duro parece "pertencer a um passado delicioso e benevolente". Embora Foucault seja considerado frequentemente o pensador por excelência da disciplina, por ter demonstrado o confinamento como tecnologia operatória e fundamental de tal poder ${ }^{9}$, Deleuze (1992, p. 215-216) sustenta nesta entrevista a Antonio Negri que o próprio autor de Vigiar e Punir "[...] é um dos primeiros a dizer que as sociedades disciplinares são aquilo que estamos deixando para trás, o que já não somos". E acrescenta: "Estamos entrando nas sociedades de controle, que funcionam não mais por confinamento, mas por controle contínuo e comunicação instantânea".

É verdade que em Nascimento da Biopolítica [1979], curso dedicado exclusivamente a uma análise contemporânea do neoliberalismo alemão e norte-americano, Foucault (2008) de fato afirma a extensão dos procedimentos de controle no espaço aberto da sociedade como o contrapeso necessário das liberdades produzidas por essa nova arte de governar que deve gerir a vida de forma processual e integral. No entanto, mesmo para essa extensão dos procedimentos de controle, que ocorrem

8 Conforme Brian Massumi (2016, p. 11) - teórico social e tradutor para o inglês de Mil platôs -, a noção de divíduo expressa a forma como Deleuze nomeia o sujeito neoliberal, cujo modelo, nos termos de Foucault (2008), é a "forma-empresa".

9 Deleuze (1986, p. 49-50) recusa, no entanto, essa classificação superficial que impede a compreensão do projeto global do pensamento de Foucault. 
não mais apenas no espaço fechado das instituições, mas também no espaço aberto administrado por essa nova razão governamental, Foucault não abre mão da noção de mecanismos disciplinares, afirmando, inclusive, que o modelo panóptico, a sua função, é a fórmula dessa política que produz liberdades ao mesmo tempo em que as controla ${ }^{10}$. Mais ao final do curso, porém, Foucault (2008) enuncia o descarte do modelo disciplinar pelo neoliberalismo, especialmente em sua forma norte-americana: o relaxamento disciplinar seria a contrapartida de uma sociedade que pretende otimizar os sistemas de diferença, abrindo espaço para processos oscilatórios e para tolerâncias em relação aos indivíduos e a suas práticas minoritárias. No manuscrito do curso, contudo, o filósofo escreve que na tecnologia de poder neoliberal não haveria o desaparecimento absoluto, mas o "recuo maciço em relação ao sistema normativo-disciplinar" (FOUCAULT, 2008, p. 355). Apenas tangenciando a dissolução da disciplina, Foucault (2008) não desenvolve a questão, sendo infiel, assim, ao anúncio de que voltaria ao tema nas aulas subsequentes.

Em Vigiar e punir - que consiste em um projeto original de "história do presente" - Foucault (1987, p. 29) também assegurava a extensão dos mecanismos disciplinares para os espaços abertos da sociedade, para além, portanto, das instituições. É o que se lê em uma seção específica do capítulo dedicado ao Panoptismo. Ali, enunciando "a ramificação dos mecanismos disciplinares" Foucault (1987, p. 174) afirma:

[...] enquanto por um lado os estabelecimentos de disciplina se multiplicam, seus mecanismos têm uma certa tendência a se desinstitucionalizar, a sair das fortalezas fechadas onde funcionavam e a circular em estado "livre"; as disciplinas maciças e compactas se decompõem em processos flexíveis de controle, que se pode transferir e adaptar. (FOUCAULT, 1987, p. 174).

Trata-se, no entanto, de uma ramificação dos mecanismos disciplinares, como a seção enuncia de modo inequívoco; o efeito disso, evidentemente, é o controle no espaço aberto da sociedade, dada a indissociabilidade do par disciplina-controle.

Ora, tais fragmentos induzem a suspeitar da afirmação deleuzeana de que Foucault teria sido o primeiro a reconhecer a passagem para as sociedades de controle, tal como a entende, em sua função específica, o autor de Post-Scriptum ${ }^{11}$.

\footnotetext{
10 "O panoptismo não é uma mecânica regional e limitada a instituições. O panoptismo, para Bentham, é uma fórmula política geral que caracteriza um tipo de governo" (FOUCAULT, 2008, p. 91-92).

11 Consonante à nossa suspeição, Michael Hardt (2000, p. 357) afirma: "Ao propor esta visão [de sociedade de controle], ele [Deleuze] afirma seguir Foucault, mas devo reconhecer que é difícil encontrar, onde quer que seja na obra de Foucault - em livros, artigos ou entrevistas -, uma formulação clara da passagem da sociedade disciplinar à sociedade de controle. De fato, ao anunciar tal passagem, Deleuze formula, após a morte de Foucault, uma ideia que não encontrou expressamente formulada na obra de Foucault".
} 
É possível que se trate, uma vez mais, de uma interpretação singular de Deleuze, que se vale do autor de Vigiar e punir (FOUCAULT, 1987) em vista de sua própria elaboração filosófica, conceitual e diagnóstica. Sabe-se, afinal, que a apropriação e o desdobramento de diferentes autores constituem um procedimento característico da démarche deleuzeana, para a qual a história da filosofia se constitui como recurso fundamental para a elaboração de um pensamento próprio ${ }^{12}$. Questionado, por exemplo, sobre seu livro Foucault (1986) e a polêmica que suscitou a propósito da questão de sua fidelidade em relação ao autor, responde Deleuze (1992, p. 111): "Nesse livro não tento falar por Foucault, mas traçar uma transversal, uma diagonal que iria forçosamente dele até mim [grifo nosso]".

Sustentando o declínio do modelo disciplinar, anunciado no segundo pós-guerra, momento em que se instaurou uma crise nas instituições, Deleuze (1992) mostra a ausência de conteúdo que parece emergir dos discursos políticos sobre reformas institucionais na prisão, no exército, no hospital e na fábrica, por estarem, elas mesmas, destinadas à liquidação. Esses seriam discursos que teriam por objetivo administrar a agonia proveniente da transformação sócio-histórica até a instalação das novas forças que se anunciam, cujas sutileza, perfeição e sofisticação de dominação exigem uma nova conceituação: as sociedades de controle. Trata-se de um novo diagrama, o qual não é preciso temer, ainda que seja necessário buscar novas armas de resistência. Para Deleuze (1992), parece inócua a indagação sobre qual regime é mais duro e mais tolerável, visto que em cada um se instituem formas de subjetivação e de sujeição, do mesmo modo que se criam formas de liberação, suas linhas de fuga - o que significa corroborar o célebre postulado foucaultiano de que não há relação de poder sem resistência (FOUCAULT, 1995).

De acordo com esse diagnóstico do presente, as fábricas são substituídas por empresas; as escolas não são mais concebidas como um confinamento com objetivo último, mas como uma etapa da formação permanente, em que o controle contínuo substitui o exame final; a busca de penas "substitutivas", ao menos para a pequena delinquência, substitui os regimes clássicos de prisões por meio de "coleiras eletrônicas" que mantêm o criminoso sob controle contínuo; os hospitais, como os psiquiátricos, dão lugar aos hospitais-dia, "sem médico nem doente". Tais substituições fundamentam a metamorfose das sociedades disciplinares para as sociedades de controle, que operam o controle de forma contínua e ilimitada. Se no regime disciplinar sempre se recomeça do zero, no plano do controle, uma vez iniciado, "nunca se termina nada" (DELEUZE, 1992, p. 221). Sublinhe-se, porém, que a noção de sociedades de controle não resulta apenas da invenção e do desenvolvimento de novos dispositivos tecnológicos informacionais, mas de uma profunda mutação do

\footnotetext{
$\overline{12}$ A esse respeito, ver Carta a um crítico severo, na qual Deleuze (1992, p. 14) designa ironicamente seu procedimento como uma espécie de "enrabada filosófica".
} 
capitalismo ${ }^{13}$. Com efeito, em Um novo cartógrafo, Deleuze (1986) sustentou a ideia de que as máquinas são sociais antes de serem técnicas.

Portanto, enquanto os meios de confinamento operavam como agenciamentos relativamente independentes que introduziam os indivíduos à necessidade de sempre recomeçar, nas sociedades de controle os agenciamentos atuam de forma absolutamente inseparáveis. A passagem da família para a escola e a empresa se constitui de modo contínuo por meio da formação permanente, implodindo assim as fronteiras anteriormente estabelecidas entre início e término e dentro e fora, visto que o indivíduo se encontra nos dias atuais em constante processo de formação e de modulação. Com a noção de formação permanente, à escola sucede-se a empresa, que pode, por sua vez, humanizar-se e transformar o humano, a um só tempo ${ }^{14}$. É nesse sentido que as chamadas técnicas de motivação, operadas em empresas para extrair dos indivíduos o máximo de eficiência, formam um modelo de captura e de modulação do humano, o qual deve se conceber no atual paradigma produtivo como empreendedor de si mesmo. Daí a necessidade política de se questionar por que os jovens solicitam insistentemente motivação, estágios e formação permanente ${ }^{15}$. Para Deleuze (1992), a atual forma humanoempresa com seu correlato sistema de prêmios tornou-se possível e real mediante esta noção - terrível, em seu entender - de formação permanente, a maneira mais sofisticada e perversa de dominação.

Se os confinamentos eram formas de moldar os corpos a fim de torná-los dóceis e úteis, o controle consiste em modulações permanentes e autodeformantes. Todavia, a modulação pode tanto funcionar de modo assustador, como o é em termos de formação permanente para o mercado - essa entidade abstrata e universal do capitalismo que produz fantástica e concretamente riqueza e miséria, tal como o define Deleuze $(1992)^{16}$-, como pode também operar de maneira liberatória. Uma breve menção a propósito da segunda forma, sem desviarmos do escopo deste estudo, reside no estatuto que o próprio Foucault atribui à autodisciplina

\footnotetext{
${ }^{13}$ A esse respeito, ver Hardt (2000), que sustenta que as sociedades de controle são imediatamente sociedades mundiais de controle em função de suas conexões com o mercado mundial, o qual, para Marx, seria o ponto de partida e de chegada do capitalismo.

${ }^{14}$ A atribuição de alma à empresa aparece para Deleuze (1992) como a notícia mais terrificante do mundo. Com efeito, salientemos que, no meio corporativo, a atual configuração do capitalismo é ilusoriamente compreendida - sobretudo por causa da teoria do capital humano, elaborada pelos economistas neoliberais da Escola de Chicago - como uma espécie de libertação dos indivíduos e de humanização das empresas (LÓPEZ-RUIZ, 2007, p. 233).

15 'Muitos jovens pedem estranhamente para serem 'motivados', e solicitam novos estágios e formação permanente; cabe a eles descobrir a que estão sendo levados a servir, assim como seus antecessores descobriram, não sem dor, a finalidade das disciplinas" (DELEUZE, 1992, p. 226).

${ }^{16} \mathrm{Na}$ entrevista a Negri, Deleuze (1992, p. 213) afirma: "No capitalismo só uma coisa é universal, o mercado". E complementa: "Ora, ele não é universalizante, homogeneizante, é uma fantástica fabricação de riqueza e de miséria. [...] Não há Estado democrático que não esteja totalmente comprometido nesta fabricação da miséria humana".
} 
em sua chamada estética da existência. Recuando ao pensamento clássico grego e romano de modo a elaborar sua ética fundada essencialmente na relação de si para consigo - o que compreende seus últimos estudos sobre História da Sexualidade ${ }^{17}$-, Foucault $(1984 ; 1985)$ mostra como é possível fazer a disciplina dobrar sobre si com finalidade liberatória (a partir de quê provém, aliás, sua noção da vida como obra de arte). Tal dobra da disciplina e do poder pode resultar, entre outras possibilidades, no cuidado de si - contrário à submissão e terceirização médicas do cuidado - notável, na modernidade, por exemplo, no discurso autobiográfico de Nietzsche $(1995)^{18}$. Em que pese o fato de que a resistência não se limite a uma decisão pessoal em face de formas de vida decadentes, devendo inscrever-se na materialidade da vida social e coletiva, o problema da modulação, característico das sociedades de controle, nos remete à pergunta nietzscheana sobre seu sentido e sua finalidade. Modula-se para que, afinal? Isto é, o investimento em si ou a formação permanente, próprios da modulação individual contemporânea, podem atender sem resistência demandas e forças externas do mercado - visando, por exemplo, acúmulo de capital humano, competitividade, empregabilidade, rentabilidade - ou podem insurgir-se criticamente contra tais finalidades externas incorporadas de maneira natural por formas de vida sujeitadas, cuja inspiração baseia-se essencialmente em valores das sociedades capitalistas contemporâneas.

Fato é que Deleuze (1992) assegura que não vivemos mais como toupeiras em sociedades disciplinares marcadas pelo aspecto sombrio das instituições, mas em meio à velocidade venenosa que delas emergiu: as sociedades de controle, para as quais resta a serpente como analogia. Portanto, ao invés dos moldes dos confinamentos, que constituem uma espécie de círculo fechado, há, nos dias atuais, tal modulação contínua e ondulatória. Daí talvez a sua provocação que não encerra uma única interpretação: "Por toda a parte o surf já substituiu os antigos esportes" (DELEUZE, 1992, p. 223). É que o controle não ocorre mais especificamente no espaço fechado das instituições, mas no espaço aberto, em que ondas contínuas modulam o sujeito empreendedor de si mesmo. No entanto, assim como procede o surfista, é preciso saber igualmente fugir à onda, ou seja, suscitar pequenos acontecimentos que escapem ao controle, afinal tal dispositivo de poder demanda o envolvimento ativo do indivíduo em suas estratégias de captura. Os anéis de uma serpente, sentencia Deleuze (1992, p. 226), "são ainda mais complicados que os buracos de uma toupeira".

\footnotetext{
17 Foi publicado o quarto volume do projeto foucaultiano de História da sexualidade, cujo subtítulo é Les aveux de la chair (As confissões da carne - tradução nossa) (FOUCAULT, 2018).

${ }^{18}$ A esse respeito, ver Andrade (2007), que estabelece relações entre os discursos autobiográficos de Nietzsche e a ética foucaultiana - compreendida enquanto efetivo experimento consigo mesmo - como forma de resistência concreta contra a subjetivação e a sujeição modernas.
} 
Observemos, por fim, as palavras com que Foucault (1987, p. 254 e 262) interrompe e conclui seu Vigiar e punir, livro incontornável no pensamento social contemporâneo sobre a noção de controle social ${ }^{19}$. Em nota de roda pé, logo após invocar o "ronco surdo da batalha", o autor adverte e remata: "Interrompo aqui este livro que deve servir como pano de fundo histórico para diversos estudos sobre o poder de normalização e sobre a formação do saber na sociedade moderna".

Como procuramos sustentar, a expressão conceitual sociedades de controle, enquanto diagnóstico do presente elaborado por Deleuze, pode mostrar como o autor de Post-Scriptum capturou à sua maneira o programa crítico de Foucault ao tomar sua pesquisa de fato como "pano de fundo histórico", atualizando- $\mathrm{a}^{20}$. O célebre enunciado de Foucault (1994, p. 76) de que "um dia, pode ser, o século será deleuzeano" 21 talvez não remeta à inocência ou à ingenuidade do autor de Foucault, como estima Deleuze (1992, p. 111-112) quando provocado a comentar o prognóstico. Não obstante sua morte cinco anos após a publicação do texto de 1990, o que o impediu de acompanhar o desenvolvimento cada vez mais sofisticado e potente das redes tecnológicas e contemporâneas de controle, o filósofo inaugurou uma interpretação inédita que nos permite ainda hoje identificar implicações que estão para além dos poderes normalizadores das sociedades disciplinares. Embora não tenha sido nosso objetivo investigar aqui os desdobramentos e as incorporações da análise deleuzeana, é preciso assinalar a existência de uma série de estudos sociológicos, políticos, antropológicos, sociotécnicos e filosóficos contemporâneos que a tomam como referência para compreender os processos de subjetivação e de controle atuais ${ }^{22}$. Em nosso estudo, procuramos mostrar, de forma específica, como o autor de Post-Scriptum estabeleceu originalmente sua análise e seu diagnóstico mediante apropriações singulares da produção teórica e empírica de Foucault.

\footnotetext{
${ }^{19}$ A esse respeito, ver Alvarez (2004), que percorre, a partir de um balanço crítico da noção de controle social, a trajetória do conceito desde o conservadorismo de Durkheim e da sociologia norte-americana até as contraposições críticas de Foucault e do debate atual em torno do conceito no pensamento social. ${ }^{20}$ A despeito das noções foucaultianas de "história" ou "ontologia" do presente (FOUCAULT, 1987; 1994a), forjadas para diagnosticar a atualidade, Deleuze (2003, p. 324-325) defende a ideia de que os livros de Foucault voltam-se mais à análise histórica (linhas de sedimentação) - sem, contudo, deixarem de tratar do presente -, ao passo que suas entrevistas versam, mais especificamente, sobre a atualidade do diagnóstico (linhas de atualização). De todo modo, em entrevista concedida em 1986 - ano de publicação de seu livro Foucault, como já ressaltamos -, Deleuze (1992, p. 131) assegura, ratificando as noções orientadoras da produção intelectual de Foucault: "Há algo essencial de um extremo a outro da obra de Foucault: ele sempre tratou de formações históricas (de curta duração, ou, no final, de longa duração), mas sempre em relação a nós, hoje".

${ }^{21}$ Sobre a amizade intelectual e política entre Foucault e Deleuze e suas rupturas, ver Eribon (2011, p. 407-416). Questionado por Eribon em 1986 sobre o motivo do livro Foucault dois anos após sua morte, Deleuze (1992, p. 118) responde: "Por necessidade minha, admiração por ele, por emoção com sua morte, com esta obra interrompida".

22 A esse respeito, ver, por exemplo, os seguintes estudos: GALLOWAY (2004); PALMÅS (2011); CRUZ (2014); ROUVROY; BERNS (2015).
}

150 Estud. sociol. Araraquara v.23 n.45 p.139-154 jul.-dez. 2018 


\title{
SOCIETIES OF CONTROL: DELEUZE'S INTERPRETATION OF FOUCAULT
}

\begin{abstract}
This study intends to show how the concept of societies of controlelaborated by Deleuze in the early 1990s as a diagnosis of contemporary societiescomes from the philosopher's updated and singular interpretation of Foucault. First, we show how the notion already appears in an embryonic format in A new cartographer, a text in which Deleuze approaches Discipline and punish, a book that has become essential in contemporary debate on social control, the very year it was published. Then we highlight the particulars of Deleuze's concept of societies of control, pointing out the limited appearance of the notion in Foucault's work. Finally, we suggest that Deleuze captured Foucault's critical program in Discipline and punish by formulating a concept whose diagnostic capability remains current contributing to the analyses of the development of networks and technological control devices.
\end{abstract}

KEYWORDS: Societies of control. Power relations. Deleuze. Foucault.

\section{SOCIEDAD DE CONTROL: LA INTERPRETACIÓN DELEUZEANA DE Foucault}

RESUMEN: Este estudio pretende mostrar como el concepto de sociedades de control - elaborado por Deleuze a principios de los años 1990 como diagnóstico de las sociedades contemporáneas - proviene de la actualización que el autor realiza de Foucault al interpretarlo de modo singular. En ese sentido, analizamos inicialmente, como la noción aparece de forma embrionaria ya en Un nuevo cartógrafo, texto en que Deleuze aborda Vigilar y castigar en el año de publicación de este libro que se tornó inevitable en el debate contemporáneo sobre control social. En secuencia, investigamos las características del concepto deleuzeano de sociedades de control, mostrando como los contornos de tal noción figura de manera limitada en la obra foucaultiana. Por último, proponemos que Deleuze captó el programa crítico de Foucault en Vigilar y castigar al formular un concepto cuya capacidad diagnóstica permanece presente en la medida en que contribuye al análisis del desarrollo de las redes y de los dispositivos tecnológicos de control.

PALABRAS CLAVE: Sociedades de control. Relaciones de poder. Deleuze. Foucault. 


\section{REFERÊNCIAS}

ANDRADE, Daniel Pereira. Nietzsche: a experiência de si como transgressão (loucura e normalidade). São Paulo: Annablume; Fapesp, 2007.

AGAMBEN, Giorgio. O que é um dispositivo? Outra travessia - Ilha de Santa Catarina, n. 5, Florianópolis-SC, p. 09-16, $2^{\circ} \mathrm{sem} / 2005$.

ALVAREZ, Marcos C. Controle social: notas em torno de uma noção polêmica. São Paulo em Perspectiva, São Paulo, n. 1, v. 18, p. 168-176, 2004.

CRUZ, Leonardo Ribeiro. Internet e arquiteturas de controle: as estratégias de repressão e inserção do mercado fonográfico digital. 2014. 271f. Tese (Doutorado em Sociologia.) Instituto de Filosofia e Ciências Humanas, Universidade Estadual de Campinas, Campinas, 2014.

DELEUZE, Gilles. Foucault. Paris: Les Éditions de Minuit, 1986.

. Conversações: 1972-1990. Rio de Janeiro: Editora 34, 1992.

. Qu'est-ce qu'un dispositif? In:

. Deux régimes de fous. Paris: Les

Éditions de Minuit, 2003, p. 316-325.

. Qu'est-ce que l'acte de création? In: . Deux régimes de fous. Paris:

Les Éditions de Minuit, 2003a, p. 291-302.

. Cours Foucault - Le Pouvoir (Janvier 1986 / Juin 1986). La voix de Gilles

Deleuze, Université Paris 8. Disponível em: <http://www2.univ-paris8.fr/deleuze/article. php3?id_article=437>. Acesso em: 20 mar. 2018.

DELEUZE, Gilles e GUATTARI, Félix. Mil Platôs. Capitalismo e Esquizofrenia. Rio de Janeiro: Editora 34, 1997.

. O anti-Édipo: Capitalismo e esquizofrenia 1. Trad. Luiz B. L. Orlandi. Rio de Janeiro: Editora 34, 2010

ERIBON, Didier. Michel Foucault, 1926-1984. Paris: Flammarion, 2011.

FOUCAULT, Michel. Microfísica do Poder. Rio de Janeiro: Graal, 1979.

História da sexualidade II: o uso dos prazeres. Rio de Janeiro: Graal, 1984.

. História da sexualidade III: o cuidado de si. Rio de Janeiro: Graal, 1985.

. Vigiar e Punir: nascimento da prisão. Petrópolis: Vozes, 1987. 

v. 2 , p. $75-99$.

. Theatrum philosophicum. In: Dits et écrits. Paris: Gallimard, 1994, . Qu'est-ce que les Lumières? In: Dits et écrits. Paris: Gallimard, 1994a, v.4, p. 679-687.

. O sujeito e o poder. In: DREYFUS, Hubert; RABINOW, Paul. Michel Foucault: uma trajetória filosófica - para além do estruturalismo e da hermenêutica. Rio de Janeiro: Forense Universitária, 1995, p. 231-249.

. Em defesa da sociedade: curso dado no Collège de France (1975-1976). São Paulo: Martins Fontes, 2005.

. Nascimento da Biopolítica: curso dado no Collège de France (1978-1979). São Paulo: Martins Fontes, 2008.

. História da sexualidade I: a vontade de saber. Rio de Janeiro: Graal, 2010.

. Histoire de la sexualité IV: Les aveux de la chair. Paris: Gallimard, 2018.

GAllOWAY, Alexander. Protocol: how control exists after decentralization. Cambridge: MIT Press, 2004.

HARDT, Michael. A sociedade mundial de controle. In: ALLIEZ, E. (Org.). Gilles Deleuze: uma vida filosófica. São Paulo: Editora 34, 2000, p. 357-372.

I THOUGHT I was seeing convicts. Direção: Harun Farocki. Documentário. Alemanha, 2000 .

KAFKA, Franz. O processo. São Paulo: Companhia das Letras, 1997.

LÓPEZ-RUIZ, Osvaldo. Os executivos das transnacionais e o espírito do capitalismo: capital humano e empreendedorismo como valores sociais. Rio de Janeiro: Azougue Editorial, 2007.

MASSUMI, Brian. O capital (se) move. São Paulo: N-1 Edições, 2016.

NABAIS, Catarina P. A dobra Deleuze-Foucault. In: CASCAIS, António F.; LEME, José L. C.; NABAIS, Nuno (Org.). Lei, Segurança e Disciplina. Trinta anos depois de Vigiar e Punir de Michel Foucault. Lisboa: CFCUL, 2009, p. 71-110.

NIETZSCHE, Friedrich. Ecce Homo: como alguém se torna o que é. São Paulo: Companhia das Letras, 1995.

OPERÁRIOS ao sair da fábrica. Direção: Harun Farocki. Documentário. Alemanha, 1995. 
PALMÅS, Karl. Predicting What You'll Do Tomorrow: Panspectric Surveillance and the contemporary Corporation. Surveillance \& Society, 8(3), p. 338-354, 2011.

ROUVROY, Antoinette; BERNS, Thomas. Governamentalidade algorítmica e perspectivas de emancipação: o díspar como condição de individuação pela relação? Revista Eco Pós (UFRJ). Rio de Janeiro, n. 2, v. 18, p. 36-56, 2015.

Recebido em 25/05/2018.

Aprovado em 06/11/2018. 